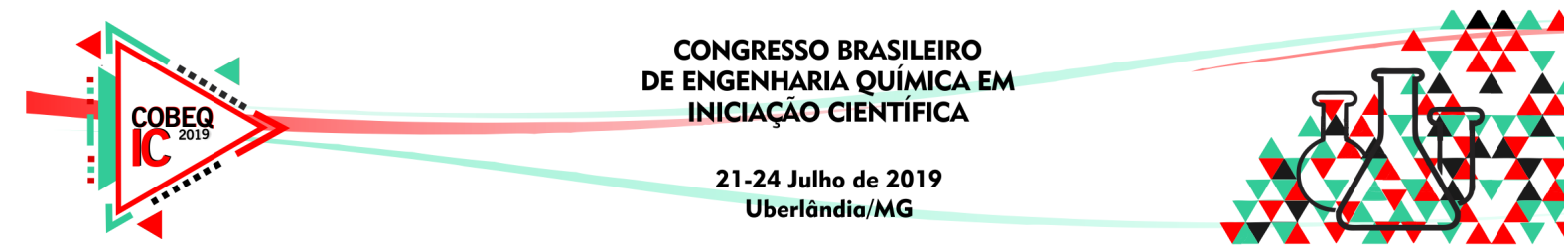

\title{
SECAGEM CONVECTIVA DE FOLHAS DE IPÊ BRANCO (Tabebuia roseo alba (Ridl.) Sand.) E AVALIAÇÃO DA DEGRADAÇÃO DE COR
}

\author{
A. C. GARDENAL ${ }^{1}$ e M. C. FERREIRA ${ }^{1}$ \\ ${ }^{1}$ Universidade Federal de São Carlos, Departamento de Engenharia Química \\ E-mail para contato: amandagardenal@yahoo.com.br
}

\begin{abstract}
RESUMO - Pesquisas recentes sugerem que o extrato da folha de ipê branco é uma alternativa inovadora ao tratamento de gota e a secagem é uma operação utilizada para garantir maior tempo de prateleira no armazenamento das folhas. O presente estudo objetiva analisar as melhores condições de secagem de tal folha, visando à preservação dos constituintes bioativos. Realizaram-se secagens de folhas de ipê branco em células de leito fixo de camada fina a fim de analisar a influência da velocidade do ar de secagem utilizado $(0,5$ e $1,0 \mathrm{~m} / \mathrm{s})$ e da temperatura do mesmo $\left(50,60\right.$ e $\left.70^{\circ} \mathrm{C}\right)$ na velocidade de secagem. Verificou-se que apenas a $50^{\circ} \mathrm{C}$ a velocidade do ar influenciou a cinética de secagem, portanto, optou-se por realizar experimentos em secador de esteira a $0,5 \mathrm{~m} / \mathrm{s}$. Por fim, avaliou-se a cinética de secagem em esteira para $50^{\circ} \mathrm{C}$ e $70^{\circ} \mathrm{C}$ a $0,5 \mathrm{~m} / \mathrm{s}$ e a qualidade do produto foi analisada a partir da degradação de cor das folhas secas, concluindo-se que a $50^{\circ} \mathrm{C}$ a cor da folha foi mais bem preservada.
\end{abstract}

\section{INTRODUÇÃO}

Um gênero de plantas amplamente difundido em território brasileiro é o Tabebuia, sendo suas folhas utilizadas há anos pela medicina popular para tratamento de câncer, tuberculose, infecção bacteriana, coagulação de sangue, doenças inflamatórias e veneno de cobra (Rahmatullah et al., 2010). Estudos realizados por Ferraz-Filha et al. $(2016 ; 2017)$ sugeriram que o extrato obtido a partir da folha de Tabebuia roseo alba (Ridl.) Sand., conhecida popularmente como "ipê branco", tem propriedades anti-hiperuricêmicas e antiinflamatórias, podendo ser um grande aliado ao tratamento da gota. Segundo a Sociedade Brasileira de Reumatologia, gota é uma doença inflamatória que acomete principalmente as articulações e ocorre quando a taxa de ácido úrico no sangue está em níveis acima do normal.

Considerando o potencial fitoterápico da folha do ipê branco e tendo em vista que as plantas, após serem colhidas, iniciam um processo irreversível de degradação devido ao aumento das suas atividades metabólicas (Rosanova, 2017), há necessidade de que tais folhas sejam secas para que possam ser armazenadas por tempos de prateleira mais longos, permitindo a produção do fármaco em grande escala. Contudo, a secagem deste material oferece vários desafios devido à variabilidade inerente da morfologia (tamanho e formato) das folhas e precisa ser feita em condições adequadas para preservar os constituintes bioativos. 


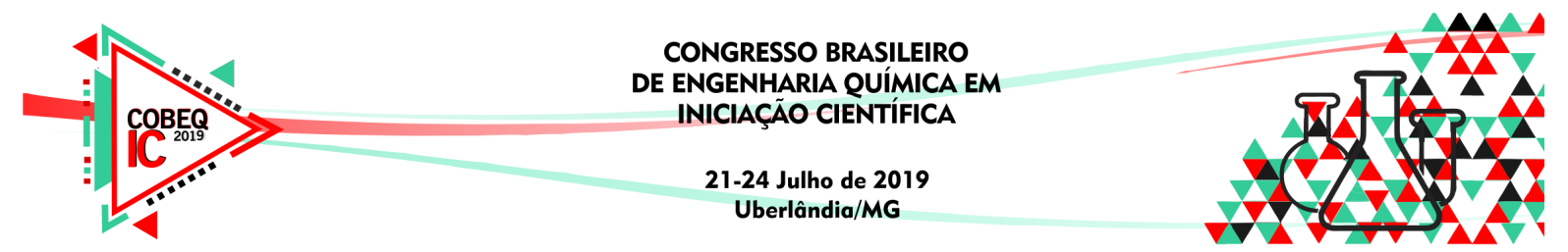

Portanto, o presente estudo objetiva analisar a secagem convectiva das folhas de Tabebuia roseo alba (Ridl.) Sand. em secador de esteira e avaliar a degradação de cor das folhas, que é considerada um bom indicativo inicial da qualidade do produto e da presença dos compostos bioativos. Visando identificar a influência da temperatura e velocidade do ar na cinética de secagem das folhas, serão feitos previamente ensaios de secagem em leito fixo em camada fina.

\section{MATERIAIS E MÉTODOS}

As secagens foram realizadas no Centro de Secagem do Departamento de Engenharia Química da Universidade Federal de São Carlos com folhas de ipê branco coletadas de árvores cultivadas no campus da própria universidade, sendo selecionadas folhas saudáveis e com boa aparência. Eventuais sujidades e materiais estranhos foram eliminados manualmente.

Os primeiros experimentos foram realizados em secador de leito fixo em camada fina, cuja área de troca térmica era aproximadamente $72,38 \mathrm{~cm}^{2}$. Cerca de $5,5 \mathrm{~g}$ de folhas eram dispostas na célula de secagem e pesadas em intervalos de tempo pré-definidos a partir do início da secagem. $\mathrm{O}$ experimento era finalizado ao se atingir uma diferença entre medidas consecutivas igual à incerteza da balança utilizada. A fim de determinar a influência da temperatura e velocidade do ar na secagem das folhas do ipê branco, foram obtidas curvas de umidade adimensionalizada, MR (Equação 1), em função do tempo de secagem para três diferentes temperaturas $\left(50,60\right.$ e $\left.70^{\circ} \mathrm{C}\right)$ e duas velocidades distintas $(0,5$ e $1,0 \mathrm{~m} / \mathrm{s})$.

$$
\mathrm{MR}=\frac{\mathrm{m}_{\mathrm{t}}-\mathrm{m}_{\mathrm{e}}}{\mathrm{m}_{\mathrm{o}}-\mathrm{m}_{\mathrm{e}}}
$$

$\mathrm{Na}$ Eq. (1), $\mathrm{m}_{\mathrm{t}}$ é a massa da folha em um tempo $t$ de secagem, $\mathrm{m}_{0}$ é a massa inicial e $\mathrm{m}_{\mathrm{e}}$ é a massa final (corresponde à condição de equilíbrio dinâmico com o ar de secagem).

A partir dos resultados obtidos na camada fina, foram determinadas as condições para a realização da cinética de secagem no secador de esteira, tal como representado na Figura 1.

Figura 1 - Esquema do secador de esteira utilizado.

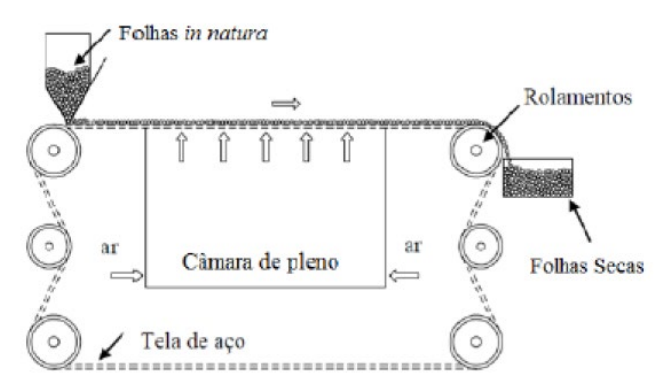

Fonte: Vieira, 2012 apud Canabarro et al., 2017

Foram usadas cerca de $48 \mathrm{~g}$ de folhas de ipê branco a cada cinética em um procedimento similar ao descrito para camada fina. A área de troca térmica, contudo, era significativamente maior, igual a $600 \mathrm{~cm}^{2}$. 


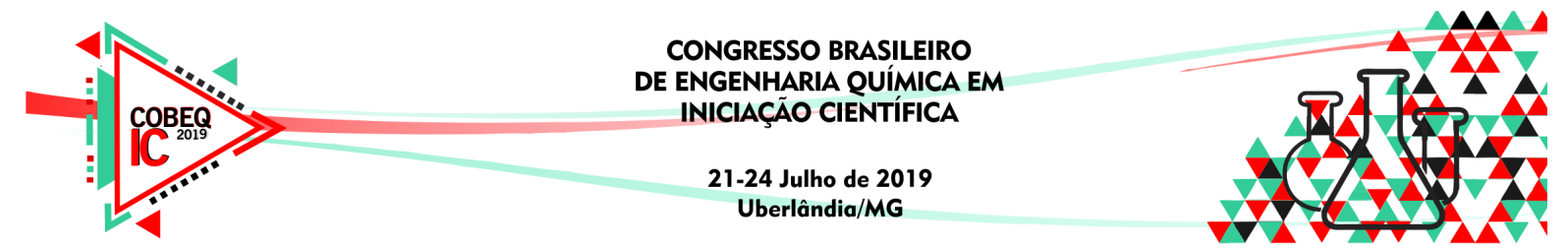

Após a realização dos experimentos, a qualidade do produto foi analisada a partir da variação de cor das folhas secas em relação às folhas in natura, sendo os resultados expressos em função do sistema de cores CIE L*a*b* obtidos pelo espectrofotômetro CM-5 da marca Konica Minolta. Os valores de $\mathrm{L}^{*}, \mathrm{a}^{*}, \mathrm{~b}^{*} \mathrm{e} \mathrm{a}^{*} / \mathrm{b}^{*}$ obtidos foram comparados, bem como a variação de cor $\left(\Delta \mathrm{E}^{*}\right)$ foi determinada a partir da Equação 2.

$$
\Delta E^{*}=\sqrt{\left(L_{f}^{*}-L_{i}^{*}\right)^{2}+\left(a_{f}^{*}-a_{i}^{*}\right)^{2}+\left(b_{f}^{*}-b_{i}^{*}\right)^{2}}
$$

$\mathrm{Na}$ Eq. (2), $\Delta \mathrm{E}^{*}$ é a diferença total de cor, L é o parâmetro que caracteriza a luminosidade, $a$ é o parâmetro que caracteriza a diferença nas tonalidades vermelho $(a>0)$ e verde $(a<0)$ e $b$ é o parâmetro de diferença em amarelo $(b>0)$ e azul $(b<0)$. Ademais, o subscrito $f$ representa a folha após a secagem, enquanto $i$ é usado para representar a folha in natura.

\section{RESULTADOS E DISCUSSÕES}

\subsection{Secagem em leito fixo de camada fina}

Na Figura 2 estão mostradas as curvas de cinética de secagem para as temperaturas do ar de $50^{\circ} \mathrm{C}(\mathrm{a}), 60^{\circ} \mathrm{C}$ (b) e $70^{\circ} \mathrm{C}$ (c) e velocidades de 0,5 e $1 \mathrm{~m} / \mathrm{s}$, respectivamente.

Figura 2 - Curvas de cinética de secagem das folhas de ipê branco em camada fina com ar de secagem a $50^{\circ} \mathrm{C}(\mathrm{a}), 60^{\circ} \mathrm{C}(\mathrm{b})$ e $70^{\circ} \mathrm{C}$ (c) e 0,5 e $1,0 \mathrm{~m} / \mathrm{s}$.
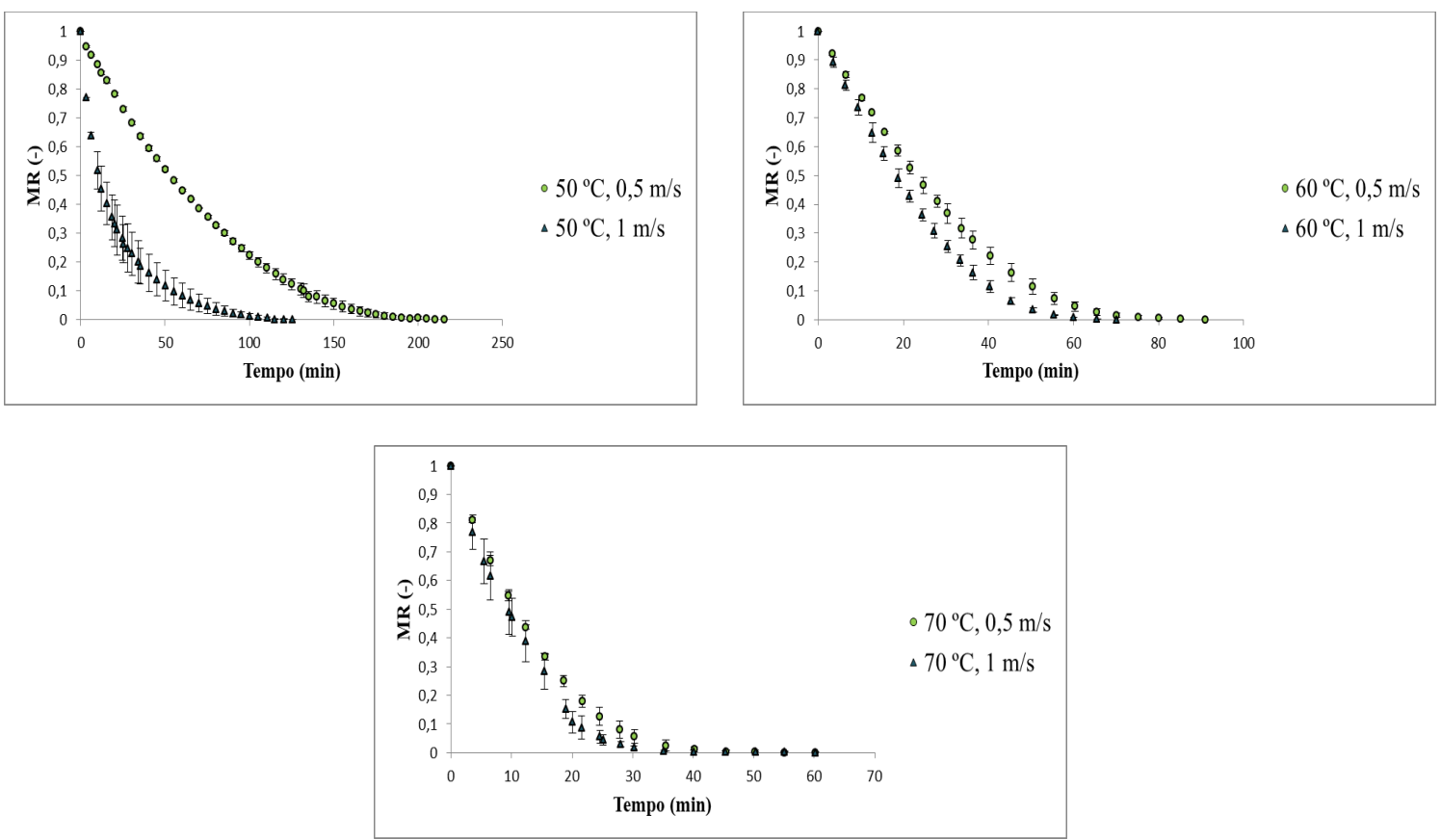

Na Figura 3(a) são apresentadas as curvas de cinética de secagem para as temperaturas do ar de 50,60 e $70^{\circ} \mathrm{C}$ à velocidade de $0,5 \mathrm{~m} / \mathrm{s}$, enquanto que as cinéticas às mesmas temperaturas com velocidade do ar de secagem a $1 \mathrm{~m} / \mathrm{s}$ são apresentadas na Figura 3(b). 


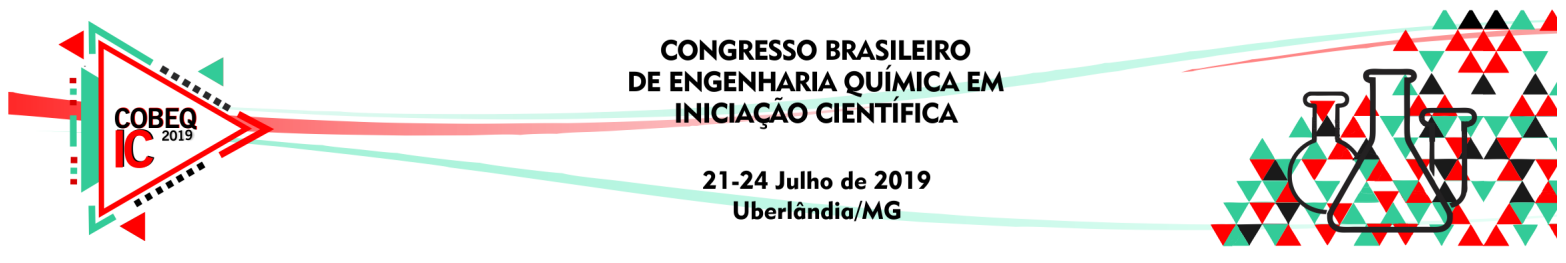

Figura 3 - Curvas de cinética de secagem das folhas de ipê branco em camada fina com ar de secagem a 50,60 e $70^{\circ} \mathrm{C}$ e velocidade de $0,5 \mathrm{~m} / \mathrm{s}$ (a) e $1,0 \mathrm{~m} / \mathrm{s}(\mathrm{b})$.
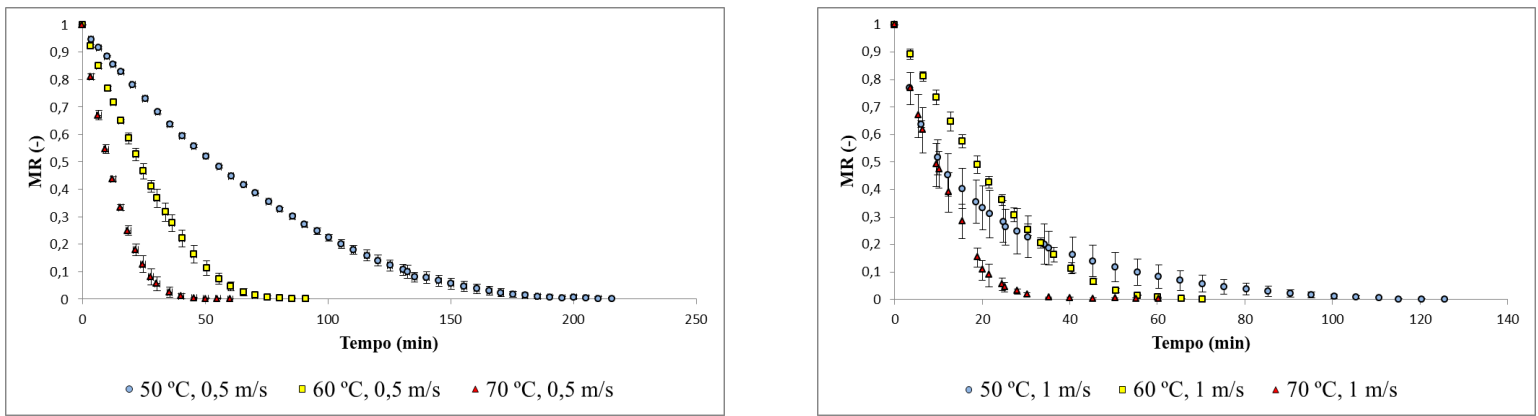

Analisando o efeito da velocidade do ar, observa-se pela Figura 2(a) que apenas a $50^{\circ} \mathrm{C}$ foi significativo o efeito da velocidade de escoamento do ar na taxa de secagem. Além disso, durante a realização do experimento, percebeu-se certa instabilidade ao operar a $1,0 \mathrm{~m} / \mathrm{s}$. $\mathrm{O}$ ar tendia a escoar preferencialmente pelas laterais devido ao encolhimento do material, gerando uma secagem heterogênea, apesar de se alcançar a umidade de equilíbrio ao fim do experimento. Isso é ilustrado na Figura 4, onde a presença de material ao fim da secagem a $70^{\circ} \mathrm{C}$ e $1 \mathrm{~m} / \mathrm{s}$ no centro da célula é um forte indício de formação de canais preferenciais junto às paredes da célula. A formação de canais preferenciais foi percebida em ambas as velocidades, porém era mais intensa a $1,0 \mathrm{~m} / \mathrm{s}$.

Figura 4 - Folhas de ipê branco in natura (a) e ao final (b) da secagem em camada fina com ar a $70^{\circ} \mathrm{C}$ e $1 \mathrm{~m} / \mathrm{s}$.
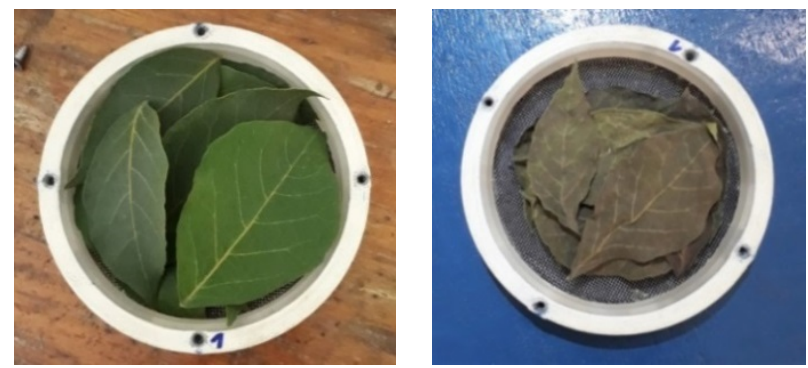

As curvas de cinética de secagem na Figura 3(a) mostram que com ar a $0,5 \mathrm{~m} / \mathrm{s}$ há uma distinção clara entre o comportamento das umidades das folhas em relação à temperatura do ar de secagem, sendo evidente a redução do tempo de secagem com o aumento da temperatura. Porém, a $1,0 \mathrm{~m} / \mathrm{s}$, conforme a Figura 3(b), as curvas são muito próximas entre si, uma vez que os desvios padrões obtidos foram relativamente altos e o efeito da temperatura não pode ser claramente observado. Tendo isto em vista, bem como o possível arraste das folhas na velocidade mais alta, além do maior gasto energético, optou-se por realizar os experimentos no secador de esteira com escoamento de ar a $0,5 \mathrm{~m} / \mathrm{s}$, às temperaturas de 50,60 e $70^{\circ} \mathrm{C}$.

\subsection{Secagem em secador de esteira}

Cinética de secagem em esteira: A Figura 5 apresenta as curvas de cinética de secagem para 50 e $70^{\circ} \mathrm{C}$ em contato com ar a $0,5 \mathrm{~m} / \mathrm{s}$. 


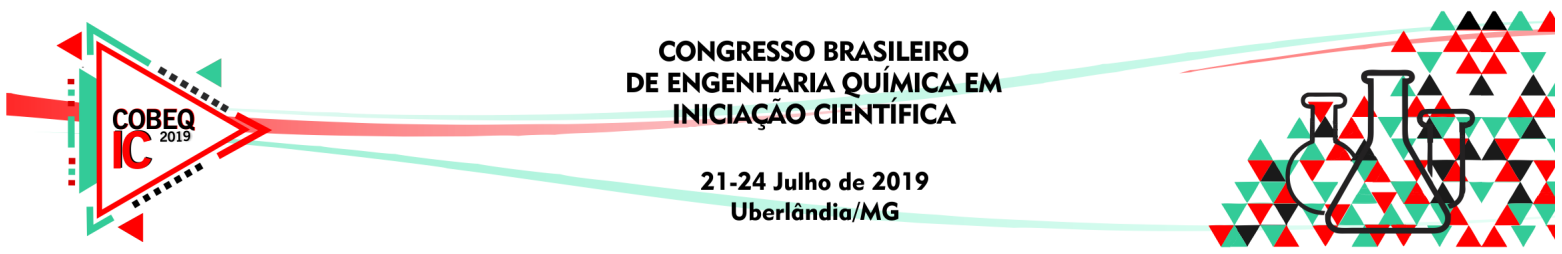

Figura 5 - Curvas de cinética de secagem das folhas de ipê branco com ar de secagem a 50 e $70^{\circ} \mathrm{C}$ à velocidade de $0,5 \mathrm{~m} / \mathrm{s}$ em secador de esteira.

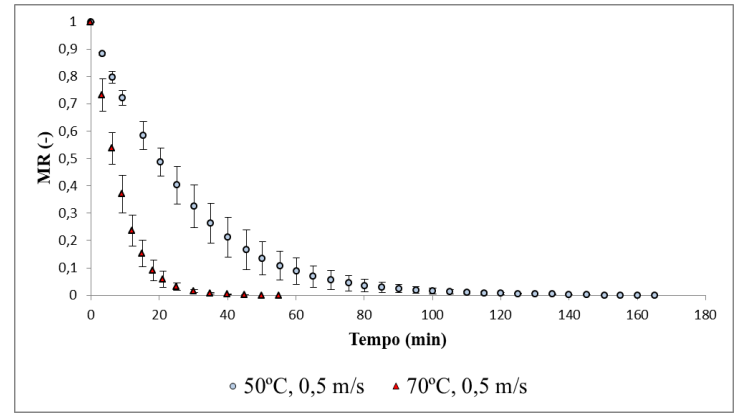

Para armazenamento, as folhas de ipê branco devem ser secas em um intervalo de 8 a 14\% de umidade em base úmida, tal como estabelecido pela Farmacopéia Brasileira IV (1988). Com base nas curvas cinéticas, calculou-se o tempo de residência que tais amostras deveriam permanecer no secador de esteira para alcançar umidade de $10 \%$, dentro da faixa recomendada. $\mathrm{O}$ cálculo foi feito correlacionando a umidade em base úmida com a umidade adimensionalizada (Eq. 1) e estimando-se o tempo de secagem nas curvas da Figura 5. Estimou-se que a $50^{\circ} \mathrm{C}$ e $0,5 \mathrm{~m} / \mathrm{s}$ as folhas devem permanecer aproximadamente 56 minutos em contato com o ar de secagem para alcançar $10 \%$ de umidade em base úmida, enquanto que a $70^{\circ} \mathrm{C}$ e $0,5 \mathrm{~m} / \mathrm{s}$ o tempo de secagem deve ser aproximadamente 17 minutos para o mesmo valor de umidade.

Avaliação da degradação de cor: As folhas obtidas nos ensaios de cinética em secador de esteira a 50 e $70^{\circ} \mathrm{C}$ e ar de secagem a $0,5 \mathrm{~m} / \mathrm{s}$ e folhas recém-colhidas de ipê branco foram utilizadas como amostras para a determinação dos parâmetros $\mathrm{L}^{*}, \mathrm{a}^{*} \mathrm{e} \mathrm{b}^{*}$ da escala de cores CIE L*a*b* em um espectrofotômetro. Os dados obtidos estão indicados na Tabela 1.

Tabela $1-$ Valores de $\Delta \mathrm{L}^{*}, \Delta \mathrm{a}^{*}, \Delta \mathrm{b}^{*}, \mathrm{a}^{*} / \mathrm{b}^{*}$ e $\Delta \mathrm{E}^{*}$ para as folhas secas a 50 e $70^{\circ} \mathrm{C}$ em relação às in natura.

\begin{tabular}{|c|c|c|c|c|c|}
\hline Amostra seca & $\Delta \mathrm{L}^{*}$ & $\Delta \mathrm{a}^{*}$ & $\Delta \mathrm{b}^{*}$ & $\mathrm{a}^{*} / \mathrm{b}^{*}$ & $\Delta \mathrm{E}^{*}$ \\
\hline \hline $50^{\circ} \mathrm{C}, 165 \mathrm{~min}$ & $-9,88 \pm 0,80$ & $5,23 \pm 0,10$ & $-3,40 \pm 0,13$ & $0,11 \pm 0,01$ & $11,69 \pm 0,67$ \\
\hline $70^{\circ} \mathrm{C}, 55 \mathrm{~min}$ & $-14,29 \pm 2,73$ & $6,04 \pm 0,04$ & $-7,45 \pm 0,72$ & $0,31 \pm 0,03$ & $17,23 \pm 2,57$ \\
\hline
\end{tabular}

A partir dos dados apresentados na Tabela 1, observa-se que a amostra seca a $50^{\circ} \mathrm{C}$ ficou menos escura que a amostra seca a $70^{\circ} \mathrm{C}$, uma vez que quanto menor o valor de $\Delta \mathrm{L}^{*}$, mais escura a amostra. As duas amostras apresentaram alteração no $\Delta \mathrm{a}^{*}$, o que indica aumento na intensidade da cor vermelha, contudo o valor apresentado pela amostra seca a $50^{\circ} \mathrm{C}$ foi menor, apontando maior preservação da coloração verde. Além disso, ambos apresentaram valores negativos de $\Delta \mathrm{b}^{*}$, indicando aproximação com o azul, porém o valor apresentado pela amostra a $50^{\circ} \mathrm{C}$ foi maior, demonstrando que a degradação do amarelo foi menos intensa. Segundo Rahimmalek e Goli (2013 apud Rosanova, 2017), o valor da razão $a^{*} / b^{*}$ é considerado um critério de avaliação da cor de produtos secos e menores valores indicam melhor qualidade, sendo assim, a amostra seca a $50^{\circ} \mathrm{C}$ e $0,5 \mathrm{~m} / \mathrm{s}$ se mostrou superior à amostra seca a $70^{\circ} \mathrm{C}$. Por fim, $\Delta \mathrm{E}^{*}$ indica a variação total de cor, sendo que o menor valor demonstra menor degradação das cores das folhas secas em comparação com as in natura, o 


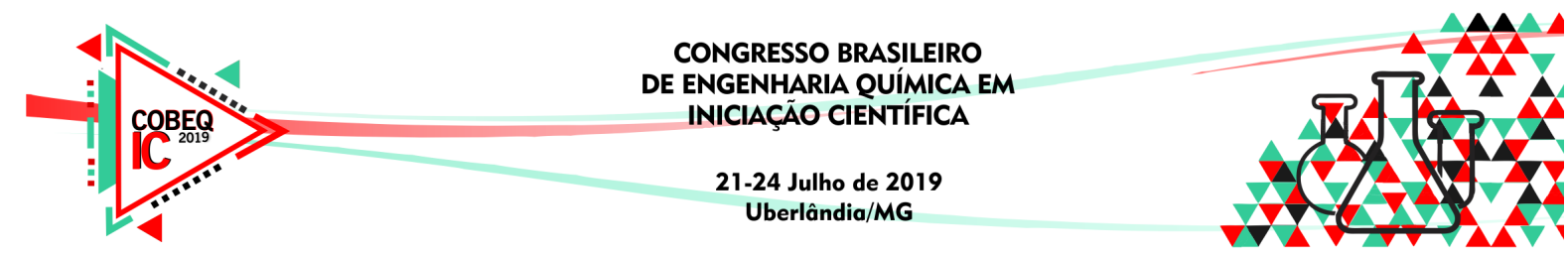

que confirma que a secagem a $50^{\circ} \mathrm{C}$ e $0,5 \mathrm{~m} / \mathrm{s}$ preservou melhor a qualidade das folhas em relação à secagem a $70^{\circ} \mathrm{C}$.

\section{CONCLUSÃO}

Por meio da análise da influência da velocidade do ar de secagem, bem como sua temperatura, em secador de leito fixo de camada fina, para as temperaturas de 50,60 e $70^{\circ} \mathrm{C}$, conclui-se que a temperatura contribui para aumentar a velocidade de secagem e que apenas a $50^{\circ} \mathrm{C}$ a velocidade do ar influenciou significativamente a cinética de secagem das folhas de ipê branco. As taxas de secagem em secador de esteira se mostraram maiores em comparação às em camada fina. Além disso, analisando a degradação de cor das folhas secas em comparação às folhas in natura, concluiu-se que a $50^{\circ} \mathrm{C}$ a degradação de cor foi menos intensa, o que indica que a qualidade das folhas secas na esteira a $50^{\circ} \mathrm{C}$ e $0,5 \mathrm{~m} / \mathrm{s}$ foi superior às secas a $70^{\circ} \mathrm{C}$ e $0,5 \mathrm{~m} / \mathrm{s}$. O estudo está em andamento e será concluído até julho de 2019 , analisando a qualidade das folhas secas em secador de esteira até a umidade prevista para o armazenamento, bem como a eficiência energética do processo.

\section{REFERENCIAS}

CANABARRO, N. I., FERREIRA, M. C. Secagem de folhas de pitangueira (Eugenia uniflora L.) em um secador de esteira e análise da influência do processo no teor e composição dos extratos obtidos via extração supercrítica. XXXVIII Congresso Brasileiro de Sistemas Particulados, 2017.

FERRAZ-FILHA, Z. S., FERRARI, F. C., MICHEL ARAÚJO, M. C., BERNANDES, A. C. F., SAÚDE-GUIMARÃES, D. A. Effects of the aqueous extract from Tabebuia roseoalba and phenolic acids on hyperuricemia and inflammation. Evidence-Based Complementary and Alternative Medicine, vol. 2017.

FERRAZ-FILHA, Z. S., MICHEL ARAÚJO, M. C., FERRARI, F. C., DUTRA, I. P., SAÚDE-GUIMARÃES, D. A. Tabebuia roseoalba: In vivo hypouricemic and antiinflammatory effects of its ethanolic extract and constituents. Planta medica, 2016.

Gota - Sociedade Brasileira de Reumatologia. Disponível em: $<$ https://www.reumatologia.org.br/doencas/principais-doencas/gota/>. Acesso em: 23 abr. 2018.

MINISTÉRIO DA SAÚDE. Farmacopéia Brasileira. Parte I. 4 ed. São Paulo: Atheneu, 1988.

RAHMATULLAH, M. S., SAMARRAI, W., JAHAN, R., RAHMAN, S., SHARMIN, N., MIAJEE, Z.U.M., CHOWDHURY, M. H., BARI, S., JAMAL, F., BASHAR, A.B.M., AZAD, A. K., AHSAN, S. An ethnomedicinal, pharmacological and phytochemical review of some Bignoniaceae family plants and a description of Bignoniaceae plants in folk medicinal uses in Bangladesh. Advances in Natural and Applied Sciences, 2010.

ROSANOVA, A. H. Desenvolvimento de um secador de tambor rotativo para a secagem de folhas condimentares e fitoterápicas. Tese de doutorado, São Carlos: UFSCar, 2017. 